\title{
A Five-Year Review of Enhanced Learning through Integration: Anatomy and Clinical Practice
}

\author{
Melanie Hagen', Brian K. Cooke ${ }^{2 *}$, Ashleigh Wright' ${ }^{1}$, Kyle E. Rarey ${ }^{3}$ \\ ${ }^{1}$ Department of Medicine, University of Florida College of Medicine, Gainesville, FL, USA \\ ${ }^{2}$ Department of Psychiatry, University of Florida College of Medicine, Gainesville, FL, USA \\ ${ }^{3}$ Department of Anatomy and Cell Biology, University of Florida College of Medicine, Gainesville, FL, USA \\ Email: ${ }^{*}$ cooke@ufl.edu
}

How to cite this paper: Hagen, M., Cooke, B. K., Wright, A., \& Rarey, K. E. (2017). A Five-Year Review of Enhanced Learning through Integration: Anatomy and Clinical Practice. Creative Education, 8, 1774-1781. https://doi.org/10.4236/ce.2017.811121

Received: July 12, 2017

Accepted: September 16, 2017

Published: September 19, 2017

Copyright (๑ 2017 by authors and Scientific Research Publishing Inc. This work is licensed under the Creative Commons Attribution International License (CC BY 4.0).

http://creativecommons.org/licenses/by/4.0/

\begin{tabular}{|c|}
\hline Open Acce \\
\hline
\end{tabular}

\begin{abstract}
Many medical schools have undergone curricula revisions and attempted to integrate basic and clinical sciences. In 2012, our program at the University of Florida College of Medicine underwent significant curricular reform, transitioning from the standard medical curriculum to a systems-based approach. The teaching of anatomy, clinical skills, radiology, ethics, population health, human behavior, and evidence-based medicine was integrated into one class, "Introduction to Clinical Medicine", which spans 68 weeks in the pre-clerkship curriculum. As a result, there was a reduction of anatomy teaching from 166 to 120 hours. Our curriculum integration demonstrates opportunities for enhanced teaching including increasing peer learning, incorporating multidisciplinary case presentations, and allowing for a deliberate overlap and layering of anatomy education across two years of medical school. This paper describes our reflection on the effect of the curriculum change on student learning. Five years after implementation of these changes shows that our efforts also illustrate the challenges inherent to curricular integration including scheduling constraints, unclear sources of financial support, apprehension about the effect on future National Board of Medical Examiners (NBME) scores, and difficulty assessing which areas a student needs to remediate within a failed integrated course. Overall, the integration of anatomy with other classes into a revised course at our College of Medicine has been well received and successful.
\end{abstract}

\section{Keywords}

Anatomy, Curriculum, Integration

\section{Introduction}

In recent years, many medical schools have implemented new curricula orga- 
nized around clinical science rather than basic science disciplines. As they work to integrate the basic and pre-clinical science course material, programs have undergone major revisions to more efficiently teach medical students. The Liaison Committee on Medical Education (LCME) advises that a medical education program "must include instructional opportunities for active learning" (Liaison Committee on Medical Education, 2013) but does not give more specific requirements. Nothing specific is mentioned about what courses could be integrated, how this integration could be implemented, and how active learning of the material should be designed.

The teaching of anatomy and clinical skills is an opportunity well suited for integration. Anatomy education does more than instill anatomical knowledge. It "may also aim to promote teamwork, enquiring, and critical thinking," (Chapman \& Hakeem, 2015) which suggests a further reason to integrate this basic science material with clinical sciences. As Turney (2007) writes, "Anatomy is obviously essential for surgeons but also has value for anyone who performs an invasive procedure on a patient; carries out emergency procedures; examines radiological imaging; performs a physical examination of a patient; refers a patient to another doctor; or explains a procedure to a patient." Anatomy education also has the potential to teach professionalism via the dissection laboratory (Jones, 2013; Swartz, 2006). Because anatomy has such relevance to all branches of medicine, there is clearly an opportunity to integrate its teaching with the rest of the medical curriculum. A vertical integration exposes students to anatomy at all levels of their training.

The integration of anatomy with basic and clinical sciences might further stimulate and promote interest in anatomy by emphasizing clinical relevance. This is crucial in the context of what some have observed as a "decline of anatomy as a result of reductions in time and resources allocated to anatomy" (Turney, 2007).

Many have shown the effectiveness of integrating and introducing ultrasound into gross anatomy curriculum (Brown et al., 2012; Hoppmann et al., 2011). This is logical not only from the perspective of integrating radiological imaging with anatomy but also for students to use hands-on technology. In fact, the linking of basic science content with a head-to-toe physical examination might be "mutually reinforcing" to both curricular components (Uchida et al., 2014).

Efforts to improve the curriculum in anatomy have included enhancing didactic teaching, computer-aided learning, use of models, inclusion of living anatomy and radiological anatomy, cadaver dissection by students, and practical lessons with prosected cadaver specimens (Patel \& Moxham, 2006). Literature review shows that many programs have described integration strategies and multiple factors contribute to successful learning, so identifying how and which interventions are successful can be challenging (Kulasegaram et al., 2013).

One medical school program reduced their anatomy course from a 16-week (130 hour) course that met three days per week to a 6.5-week course (with 41 
hours of lectures) that met daily up to 4 hours (Halliday et al., 2015). Amongst other changes, this new course had integration of clinical concepts by practicing clinicians presenting cases and radiological images associated with the anatomical regions. Preliminary results suggest that this compressed curriculum was at least as effective (Halliday et al., 2015).

Students who receive anatomy education with three-dimensional dissection models perform better on testing than those who receive conventional, twodimensional teaching (Brinke et al., 2014). An extension of this idea might be that other three-dimensional teaching could enhance anatomy learning. This three-dimensional teaching might include the integration of physical examination teaching.

Curriculum integration is not without potential disadvantages and drawbacks. Integration disrupts a normal sequence of education when other course material is interspersed in a thematic curriculum. For example, some have argued that it is challenging to integrate human anatomy, because of its regional approach, with more systems-based courses (Bolender et al., 2013). McKeown et al. (2003) showed that introduction of a systems-based course had a negative impact on medical students' knowledge of surface anatomy of the limbs and abdomen.

This paper aims to describe the process that one US medical school underwent when reforming its curriculum to a systems-based approach. We will describe the strengths and weaknesses of these changes. The resources, both in faculty time and learning materials, are also discussed. We describe the outcomes from five years of curricular reform and opportunities for success despite concerns about scheduling constraints, sources of financial support, and the effect on future National Board of Medical Examiners (NBME) scores.

\section{Methods}

In 2012, the University of Florida College of Medicine underwent significant curricular reform, transitioning from the standard medical curriculum to a systems-based approach. We integrated the teaching of anatomy, clinical skills, radiology, ethics, population health, human behavior, and evidence-based medicine into one class, "Introduction to Clinical Medicine" (ICM). ICM spans the pre-clinical curriculum, a total of 68 weeks. Although this integration provided an opportunity to teach anatomy in a method meaningful to physical examination and clinical diagnosis, it also disrupted the traditional one-semester dissection-based anatomy curriculum. Additionally, the amount of teaching time for anatomy was decreased from 166 to 120 hours total, making it necessary that the teaching time that remained be used very efficiently.

We modified the anatomy course in a way that allowed maximum applicability to other courses' content. In the first semester of ICM, students are taught the entire physical examination to prepare for a primary care preceptorship. During this semester, they study prosections of anatomical specimens, with nine cadaver specimens for 135 students, and are taught anatomy as it relates to the physical 
examination. More detailed instruction is reserved for the second through fourth semesters, during the relevant systems modules. These modules, which are not part of ICM, teach physiology, pathology and pharmacology of the various body systems, and are three to seven weeks in length. One challenge has been that the density of gross anatomy and clinical examination to be taught does not always parallel the length of the block. A significant example of this is the musculoskeletal block, which is only four weeks long, but is an area where students frequently struggle with anatomy and physical examination skills.

Our program has also incorporated bedside ultrasound and CT imaging modalities to reinforce the physical examination. The use of ultrasound spans the pre-clinical years and is taught in small groups by physicians specializing in bedside ultrasound. Students learn and practice ultrasound techniques relevant to the concomitant module. CT scans are performed on all cadavers, allowing students to have a unique experience in relating two-dimensional imaging to a three-dimensional specimen, which they can hold and manipulate.

Our anatomy instruction allows for active learning. Students compare CT images of structures on their own cadavers to identical structures in the cadaver in the "Visual Human Dissector" program and CT scans of living patients with intravenous contrast. They label five identical structures in cross section on both images (Figure 1). After being checked for accuracy, these are uploaded to the course website. As these peer-created questions may appear on examinations, this process enhances peer learning and enhances their studying.

Assessment of knowledge of anatomy is integrated into the quizzes and examinations for the ICM course through multiple-choice, clinically oriented questions. Students are also tested with three to four practical examinations of anatomy content per semester. These include wet specimens, axial, sagittal and coronal CT sections and images from the Visual Human Dissector program. Each practical exam contains approximately 50 questions.

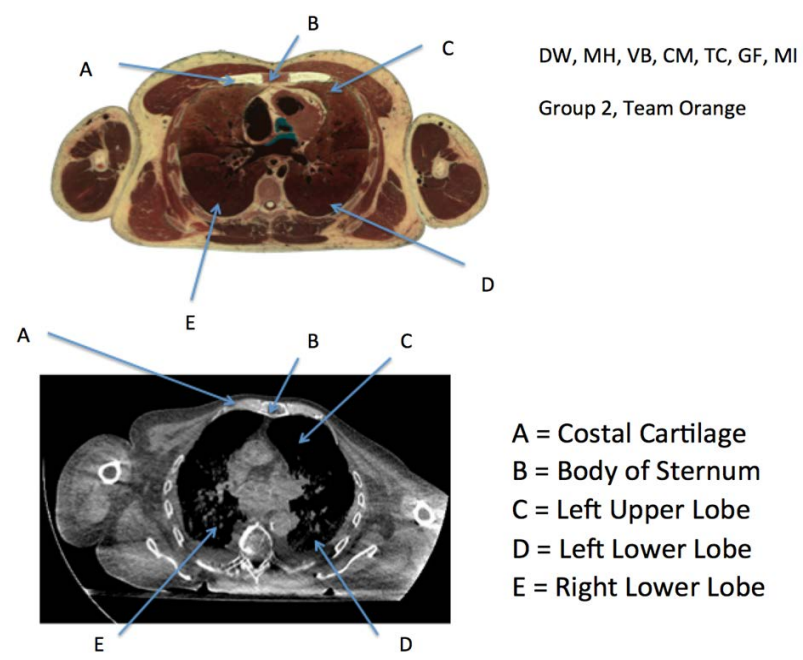

Figure 1. Example of student-submitted group assignment to identify and label five identical structures in cross section. 
Another way that we have integrated anatomy and clinical medicine is through multidisciplinary patient case presentations. A clinician interviews a patient in front of the class, and then the class discusses the symptoms and comes up with a differential diagnosis. A radiologist presents relevant diagnostic images. The physicians and an anatomist discuss the findings and narrow the differential diagnosis. The patient then describes his or her experience with the diagnosis and treatment. Examples of patient presentations presented in this format are cholecystitis, abdominal aortic aneurysm, and breast cancer.

\section{Outcomes}

We are currently in our fifth year of the integrated curriculum. There have been many positive outcomes and strengths of our integration of anatomy and clinical medicine. The layering of knowledge over time allows for deeper understanding and improved retention of the material. This presents the opportunity for information to progress from short-term to long-term memory. In the first semester, while working in parallel with learning the physical exam, students learn the language of anatomy. In the next three semesters they apply this acquired vocabulary to more complex anatomical concepts.

Students and faculty have noticed an improved ability of students to connect human anatomy with three-dimensional imaging and physical exam. Students no longer memorize textbook images of the body; now, they have a more three-dimensional understanding of anatomy. Opportunities exist for reinforcing knowledge about anatomy and about physical exam when the basic anatomic structures are revisited in the systems modules. By teaching the anatomy in more detail in the systems modules, functional anatomy is further highlighted. Students have demonstrated an increase in their appreciation of learning at the bedside. All of this was accomplished while still decreasing the hours of anatomy lecture and lab from 166 to 120.

We were happy to note that scores on the gross anatomy and embryology portion of the NBME Step 1 Exam have been relatively higher for students who started the new curriculum compared to the national average than those students who started the year prior to the new curriculum. This was not the case for other subject areas on the exam. This reinforces our impression that our students have a deeper understanding and improved retention of the anatomy of the human body.

The integration of anatomy and clinical medicine has not been without challenges. For some programs, these challenges may be difficult to overcome and could represent drawbacks to reforming curriculum. Navigating the new curriculum with a large team has led to struggles with content and with logistics. Faculty from medical education, clinical medicine departments, anatomy, radiology, and bedside ultrasound have different educational priorities and schedules. We have had to be very specific about who is responsible for what aspect of the content and what content needs to be repeated and reinforced. We have needed 
to be flexible about scheduling activities where faculty from several departments are involved.

Student assessment has presented challenges as well. It can be difficult to adequately evaluate student performance on content that contains blended topics. Yet the successful integration and overlap offunctional anatomy with clinical medicine in our longitudinal curriculum has resulted in multiple learning modalities and assessment opportunities. Using subject tags for each quiz or exam question and tracking student performance in each subject area has helped to identify such deficiencies. The College of Medicine created a uniform collection of tags, which identify topics by both competency and discipline topic.

We felt that it was important to include bedside ultrasound in the course since it is a relatively easy to use technology that illuminates anatomy at the patient's bedside. Bedside ultrasound users from the department of Emergency Medicine were the most enthusiastic about early involvement, partly due to the radiologists' preference to teach a more comprehensive approach to ultrasound interpretation. Through negotiation and compromise, both departments are included in teaching the ICM course.

Although there was some concern about preserving cadavers longer than a semester, this did not turn out to be a problem. The cadavers were stored promptly and removed only when needed. Quality of specimens proved to be adequate.

\section{Conclusion}

A clear vision of the curricular goals with careful thinking is necessary when integrating courses. Although there is a potential loss of material and sequence when courses are integrated, there is the potential gain of implementing a more effective way of presenting the material. Drake has offered four guiding principles to course directors who are considering how to modify programs in an integrated or mixed curriculum: presentation of material should promote active learning; a variety of educational experiences should be used; incorporating a closer integration with clinical medicine throughout the course gives motivation; learning should be longitudinal (Drake, 2014).

The ICM course has been successful in promoting active learning and including a variety of educational experiences. We have added activities that challenge students to create clinical and identification questions to help each other to study. Students participate in interviews and developing a differential diagnosis. CT scans of cadavers are used to demonstrate how spatial relationships in three dimensions are represented in imaging. Bedside ultrasound is used to help students appreciate the link between the physical examination and anatomy.

Our course succeeds by giving students a strong motivation to learn clinical anatomy as well as an opportunity to learn longitudinally. They see how clinical anatomy is used to diagnose and treat disease from the first day of class. They 
use their knowledge of surface anatomy and deeper structures when performing the physical exam. Finally, by returning to concepts repeatedly, students commit content about clinical anatomy to deeper memory.

\section{References}

Bolender, D., Ettarh, R., Jerrett, D., \& Laherty, R. (2013). Curricular Integration = Course Disintegration: What Does This Mean for Anatomy? Anatomical Sciences Education, 6, 205-208. https://doi.org/10.1002/ase.1320

Brinke, B., Klitsie, P., Timman, R., Busschbach, J., Lange, J., \& Kleinrensink, G. (2014). Anatomy Education and Classroom versus Laparoscopic Dissection-Based Training: A Randomized Study at One Medical School. Academic Medicine, 89, 806-810. https://doi.org/10.1097/ACM.0000000000000223

Brown, B., Adhikari, S., Marx, J., Lander, L., \& Todd, G. (2012). Introduction of Ultrasound into Gross Anatomy Curriculum: Perceptions of Medical Students. The Journal of Emergency Medicine, 43, 1098-1102. https://doi.org/10.1016/j.jemermed.2012.01.041

Chapman, S., \& Hakeem, A. (2015). Letter to the Editor: Undergraduate Anatomy Teaching: Evaluations and Conclusions. Academic Medicine, 90, 399.

Drake, R. (2014). A Retrospective and Prospective Look at Medical Education in the United States: Trends Shaping Anatomical Sciences Education. Journal of Anatomy, 224, 256-260. https://doi.org/10.1111/joa.12054

Halliday, N., O’Donoghue, D., Klump, K., \& Thompson, B. (2015). Human Structure in Six and One-Half Weeks: One Approach to Providing Foundational Anatomical Competency in an Era of Compressed Medical School Anatomy Curricula. Anatomical Sciences Education, 8, 149-157. https://doi.org/10.1002/ase.1476

Hoppmann, R., Rao, V., Poston, M., Howe, D., Hunt, P., Fowler, S., Paulman, L., Wells, J., Richeson, N., Catalana, P., \& Thomas, L. (2011). An Integrated Curriculum (iUSC) for Medical Students: 4-Year Experience. Critical Ultrasound Journal, 3, 1-12. https://doi.org/10.1007/s13089-011-0052-9

Jones, T. (2013). Creating a Longitudinal Environment of Awareness: Teaching Professionalism outside the Anatomy Laboratory. Academic Medicine, 88, 304-308. https://doi.org/10.1097/ACM.0b013e318280f075

Kulasegaram, K., Martimianakis, M., Mylopoulos, M., Whitehead, C., \& Woods, N. (2013). Cognition before Curriculum: Rethinking Integration of Basic Science and Clinical Learning. Academic Medicine, 88, 1578-1585. https://doi.org/10.1097/ACM.0b013e3182a45def

Liaison Committee on Medical Education (2013). Functions and Structure of a Medical School: Standards for Accreditation of Medical Education Programs Leading to the M.D. Degree.

McKeown, P., Heylings, D., Stevenson, M., McKelvey, K., Nixon, J., \& McCluskey, D. (2003). The Impact of Curricular Change on Medical Students' Knowledge of Anatomy. Medical Education, 37, 954-961. https://doi.org/10.1046/j.1365-2923.2003.01670.x

Patel, K., \& Moxham, B. (2006). Attitudes of Professional Anatomists to Curricular Change. Clinical Anatomy, 19, 132-141. https://doi.org/10.1002/ca.20249

Swartz, W. (2006). Using Gross Anatomy to Teach and Assess Professionalism in the First Year of Medical School. Clinical Anatomy, 19, 437-441. https://doi.org/10.1002/ca.20331

Turney, B. (2007). Anatomy in a Modern Medical Curriculum. Annals of the Royal Col- 
lege of Surgeons of England, 89, 104-107.

Uchida, T., Farnan, J., Schwartz, J., \& Heiman, H. (2014). Teaching the Physical Examination: A Longitudinal Strategy for Tomorrow's Physicians. Academic Medicine, 89, 373-375. https://doi.org/10.1097/ACM.0000000000000136

\section{Scientific Research Publishing}

Submit or recommend next manuscript to SCIRP and we will provide best service for you:

Accepting pre-submission inquiries through Email, Facebook, LinkedIn, Twitter, etc. A wide selection of journals (inclusive of 9 subjects, more than 200 journals)

Providing 24-hour high-quality service

User-friendly online submission system

Fair and swift peer-review system

Efficient typesetting and proofreading procedure

Display of the result of downloads and visits, as well as the number of cited articles Maximum dissemination of your research work

Submit your manuscript at: http://papersubmission.scirp.org/

Or contact ce@scirp.org 